\section{Man or machine in space}

SIR - Your leading article on the US manned space programme (Nature 307, 1; 1984 ) is uninformed and unfair. The view that there can only be manned or unmanned space exploration is a needlessly adversarial position. The National Aeronautics and Space Administration (NASA) actively supports both programmes, which are inexorably linked by spacecraft support and technological advances.

The lack of new unmanned planetary projects is more the consequence of decreased funding than deliberate policy. In the short term, planned unmanned space exploration is dependent on shuttle technology; the Galileo, Mariner Mark II, Observer and Spartan programmes all require it. Moreover, the shuttle and an orbital platform are the key to the future of unmanned planetary exploration. The blanket statement that the shuttle harms planetary science is unfair, shortsighted, and untrue.

So are the statements regarding the historic Apollo programme. The successes of Pioneer, Voyager and Viking depended and continue to depend on technology developed for the Ranger and Surveyor programmes, which were in turn developed for Apollo. Furthermore, the only significant quantities of extraterrestrial materials ever examined by scientists were returned by, as your writer quoted Tom Lehrer, "some clown on the Moon". The statement that Apollo led "nowhere" overlooks at least 16 articles on Apollorelated research published in Nature between 1970 and 1972 alone ${ }^{I}$.

Your statement that a manned space platform would yield "two decades of original research on why astronauts vomit and whether you can make the perfect ballbearing in space" demonstrates a lack of familiarity with the findings from Salyut, Skylab and recent shuttle flights. Such a platform will have many uses including satellite repair and maintenance, materials processing, astronomy, biology and basing for unmanned planetary probes.

Your rather shortsighted implication that a manned space platform may be needed in the future, but not right now, smacks of the philosophy of Senator William Proxmire who recently awarded the Golden Fleece Award to NASA, stating that because the planets have been there for "millions of years, and will be around for millions more", there is no hurry to investigate them.

Your leading article underscores a major problem in research planning: short term versus long term. Technology developed for either the manned or unmanned programme ends up in the other, and both projects benefit. Adherents of the two philosophies should not bicker, but should join forces to lobby for increased funds. Most importantly, emphasis should be placed on long-term planning of manned and unmanned space exploration. The shuttle and a permanently manned orbital platform are a good first step.

MARK OWEN MARTIN Department of Biological Sciences,

Stanford University,

Stanford, California 94306 USA

1. Nature 226. 925 (1970); 228, 254 (1970); 232. 94; 234, 211, 402 (1971); 236, 215, 381 (1972); 237, 158, 446 (1972); 238. $450(1972) ; 239,205$ (1972); 240, 94, 95, 96, 139, 259 (1972).

\section{Plum pox virus}

SIR - In Nature $(303,365 ; 1984)$ under the title "Italy's farmers battle with virus", Robert Walgate described an outbreak of plum pox virus (PPV) around Turin and Bologna. In that article, the phytopathological problem appeared dramatic. I would like to modify the impressions given, and describe the present situation.

The Italian Ministry of Agriculture was informed of the outbreak soon after its discovery, in August 1982. In November 1982, it sent a letter to the regional phytopathological service ordering the destruction of all affected trees. On compensation, the regional administration of Piedmont has agreed to supply healthy trees free of charge to replace those destroyed.

Eradication of infected trees was, however, begun immediately by personnel of the regional phytopathological service. All trees in orchards in the affected area were screened individually for PPV symptoms. The apparently infected plants and those surrounding them were checked for PPV serologically at this institute. The results of this survey will be presented at the "Giornate Fitopatologiche" to be held in Sorrento (Naples) on 29 March 1984. They can be summarized as follows.

PPV was detected only in apricots and in some suckers from wild peach and mirabolan rootstocks of infected apricots, but not in peaches or plums. The outbreak appeared restricted to about 2,500 hectares of cultivated land. During 1982 and 1983 more than 15,000 plants were screened and some 1,400 found to be infected. The two main virus foci detected in 1982 (500 trees) were destroyed the same year while seven other foci detected in 1983 are to be destroyed during the present winter.

The spread of PPV in Piedmont seems to have occurred mostly by vegetative propagation. In only a few cases does the gradient of incidence in the orchards suggest that secondary spread of virus by aphids may have occurred.

These result allow us to hope that the outbreak of PPV may be contained this year. It may even be possible to eradicate PPV from the area within a few years, although in other countries eradication has proved difficult. MAURIZIO CONTI Instituto di Fitovirologia applicata, Consiglio Nazionale delle Ricerche, Turin, Italy

\section{Dietary cholesterol}

SIR - The Lipid Research Clinics Coronary Primary Prevention Trial (LRCCPPT) showed conclusively that lowering of serum cholesterol by means of a bile acid sequestrating drug reduced the chance of a heart attack. Your editorial' suggests that this does not prove the benefit of a reduction in cholesterol intake, because dietary cholesterol has too little influence on blood cholesterol levels in man.

Such a statement combines two errors. First, it equates a cholesterol-lowering diet with a low-cholesterol diet. In man, however, the most important determinant of serum cholesterol is not the amount of cholesterol in the diet but that of saturated fatty acids. Reduction of saturated fatty acid (and cholesterol) intake, combined with an increased consumption of polyunsaturated fatty acids, reduced serum cholesterol by 10 to 15 per cent or more in several long-term mass field trials ${ }^{2}$. This contrasts with 8.5 per cent in LRC-CPPT, which is typical for other drug trials as well ${ }^{2}$. So diet is generally more effective than drugs in lowering cholesterol.

A second error is the suggestion that dietary cholesterol has a negligible effect on serum cholesterol. It is true that if one already eats two eggs a day (equivalent to about $500 \mathrm{mg}$ of cholesterol) one might as well eat four as far as serum cholesterol is concerned, because there is a saturation effect. However, reduction of daily cholesterol intake from the usual US or British intake of about $500 \mathrm{mg}$ to $200 \mathrm{mg}$ will reliably lower serum cholesterol by 4 per cent on average, and by more than that in "hyperresponders" with high sensitivity to dietary cholesterol ${ }^{3}$. Thus the effect of cholesterol in the diet is small, but not unimportant.

Department of Human Nutrition,

Agricultural University,

De Dreijen 12, 6703 BC Wageningen,

The Netherlands

Department of Laboratory

Animal Science,

State University,

Yalelaan 1, 3508 TD Utrecht,

The Netherlands

1. Nature 307, 205 (1984)

. Rifkind, B.M., Goor, R. \& Schucker, B. Atherosclerosis Vol.6 306-310 (Springer, Berlin, 1983).

Katan, M. B. \& Beynen, A.C. Lancet i, 1213 (1983).

\section{Effect and affect}

SIR - I should like to draw attention to the recent North American fashion for the use of the word "affect" as a noun. The usage seems to have spread like a forest fire through my American colleagues. 1 tell them that they can "affect an effect" but not "effect an affect". But they take no notice and persist in this affectation.

R. C. Watkins

Esso Chemical Research Centre,

PO Box 1, Abingdon,

Oxfordshire $O X 136 B B, U K$ 